Submitted: 21.07.2016.

Accepted for publication: 01.12.2016.

\title{
Media Traumatization, Symbolic Wounds and Digital Culture
}

\author{
Allen Meek ${ }^{1}$ \\ Massey University, New Zealand
}

doi: $10.5937 /$ comman11-11442

Abstract: Do media images really traumatize the public? If they do not, then why do so many commentators - from those commemorating the Holocaust to those analysing the impact of 9/11 - claim that trauma can be transmitted to specific ethnic groups or entire societies? While these claims can be based on empirical data or used to justify political agendas, psychoanalysis also continues to influence conceptions of collective trauma and to offer important perspectives for evaluating these conceptions. This paper explores these questions of mediated trauma and collective identity by tracing a neglected historical trajectory back to the work of psychoanalyst and anthropologist Geza Roheim. Roheim produced studies of Australian Aboriginal culture that applied the theory of collective trauma outlined in Freud's Totem and Taboo. He also produced an ethnographic film, Subincision, documenting an initiation rite, that was subsequently used in psychological studies of so-called "stress films". Putting aside Roheim's psychoanalytic interpretations of indigenous culture, psychologists used his film to measure the impact of images of violence and pain. These studies from the 1960s have recently been rediscovered by scholars of Holocaust film and video testimony. This paper seeks to recover the concept of "symbolic wounds" developed in psychoanalyst Bruno Bettelheim's later commentary on Roheim's work. The mass media of newspapers, film and television have supported the idea of cultural trauma shared by large societies. The concept of symbolic wounds that enhance group membership and mobilize collective action may be more useful for understanding how violent and shocking images are put to more diverse uses in digital culture.

Keywords: trauma, stress film, symbolic wounds, September 11, ISIS, Black Lives Matter

\footnotetext{
Contact with author: A.Meek@massey.ac.nz.
} 


\section{Introduction}

Research on media traumatization has attempted to explain the psychological impact of images showing violent and catastrophic events (Holmes \& Bourne, 2008). Images that show pain and suffering can be understood to cause pain and suffering for viewers, even if the experience shown and the experience of seeing are understood as qualitatively different. Psychoanalysis has made an important contribution to this area of research by explaining how identification with "traumatic" images is driven by unconscious fears and desires, and how the psyche protects or "numbs" itself against the impact of shock (Freud, 1920; Lifton, 1967). Psychoanalytic accounts that emphasize the role of interior processes of identification, however, have tended to be discounted in research that focuses on the traumatic impact of media images as external stimuli. In order to address this neglected perspective the following discussion seeks to recover a conception of "symbolic wounds" from the works of psychoanalysts Geza Roheim and Bruno Bettelheim (Roheim, 1950; Bettelheim, 1955). Roheim and Bettelheim both argued, in different ways, that violence can have symbolic value that enables social participation and group membership. The following discussion proposes that media images can function as symbolic wounds inviting active identification. I propose that discourses about media traumatization have been dominated by the idea of cultural trauma, which depends on a onesource-to-many-viewers model of mass media. The idea of symbolic wounds better describes the situation made possible by digital media, where new communities emerge in relation to images of violence and suffering, revealing how such images can not only distress or desensitize but also enhance and empower those who look at them.

Claims that media images can induce or transmit traumatic experience have been made about photographs, documentary films, television news and video testimony (Sontag, 1977; Felman \& Laub, 1992; Hirsch, 2004; Neria, Di Grande \& Adams, 2011). These claims have been associated with the mass media of print, cinema and television because they assume that a single source of information is being received by potentially very large audiences. When entire societies are likely to encounter particular images of violence and catastrophe then public figures, intellectuals and media professionals engage in the discursive construction of cultural traumas (Alexander, 2012): when everyone sees the same images they can be said to experience similar emotional responses. 
Probably the most widely known example of this construction of a cultural trauma is the narrative about Americans' shocked response to witnessing the events of September 11, 2001. The possibility that there has never actually been such uniformity of feeling becomes more evident with the greater multiplicity of images and narratives available on the Internet, showing that violent images invite a range of responses that include not only dismay and rage but also "inappropriate" ones such as fascination and amusement. The shift to digital technologies has allowed media users to navigate almost limitless amounts of information, develop individual user profiles and participate in social networks. The proliferation of media images and texts potentially available at any time or place, along with the intensification of explicit violence and horror, make this less predictable encounter with the "traumatic" image a significant feature of media use today (Meek, 2010; Morpurgo, 2016).

Psychoanalysis can help us to understand how the social and cultural value of symbolic wounds has changed in response to historical developments in modern media. Freud understood identity formation in terms of the child's relation to his/her parents in the private domestic space: the child internalized parental authority in the form of the super-ego, which was understood by Freud as specifically patriarchal and middle-class. In Freud's time parental authority over the child's auto-erotic tendencies was commonly expressed through threats of castration (Poster, 2006: 165-168), a symbolic wound that structured cultural identity through sexual repression. Mark Poster argues that because childhood development today is strongly shaped by media technologies, the private relationship between a child and his/her parents has been displaced by the child as a consumer and member of specific target markets. Young people now use a diverse range of media, over which parents exercise limited control (Poster, 2006: 171-173). This situation developed gradually in the second half of the twentieth century, when private life was increasingly characterized by the consumption of newspapers, magazines, television and movies. During this period mass media assumed the role of constructing narratives about national identity and collective traumas. The televisual nature of these traumas can be seen in examples such as the 1961 Eichmann trial, the assassination of John F. Kennedy and the $9 / 11$ attacks. New traumatic images of war, famine and death became available but remained centrally controlled and censored by corporate media. In psychoanalytic terms these traumatic images could be understood as induc- 
ing castration anxiety and thereby prompting identification with a national or ethnic superego.

In the mid-1990s trauma studies suggested new approaches to the question of media traumatization by bringing together psychoanalysis, psychotherapy with Holocaust survivors, and recorded testimony in film and video. The influential work of Cathy Caruth and Shoshana Felman sought to recover forgotten historical experience through the transmission of traumatic shock in literary, film and video texts (Felman \& Laub, 1992; Caruth, 1996). Psychoanalysis explains traumatic experiences as overwhelming conscious understanding, allowing the unconscious memory of the event to return in symptoms such as nightmares, compulsive behaviours, and other neuroses and pathologies. By analogy, these trauma theorists argued that extreme events resist understanding at the time of their occurrence and reappear as symptomatic disruptions in later representations of history. The emphasis on the collective experience of catastrophe, however, implicitly leads us back to the question of media as an apparatus of power. The political implications of identification with traumatic histories became clearer after the "live" transmission of the 9/11 attacks on television, when many media commentators almost immediately made claims about collective trauma for Americans (Trimarco \& Depret, 2005: 30). The "superego" effect of the state and mass media was revealed in subsequent military interventions and intensified national security and social surveillance. The televisual replay of numerous different video recordings made by private citizens appeared to act out the experience of the events as an intrusive memory. National surveys conducted after the $9 / 11$ attacks led to claims of substantial levels of stress and PTSD among the general population (Young, 2007: 28). In this case psychological research appeared to directly serve the interests of a narrative of national trauma.

Both these theoretical and empirical accounts of the psychological impact of 'traumatic' images assumed a single-source-to-multiple-viewer model. Attempts to understand the impact of traumatic images tend to assign roles of perpetrator and victim, using actions in real life events to define a relation between media and viewer. Psychoanalysis, however, includes more complicated accounts of relationships between perpetrator and victim, including fantasy and guilt. Nevertheless, as Ruth Leys $(2000,2007)$ has shown, both trauma theory and psychological studies of traumatic images have tended to reproduce the 
model of impact from an external source and to discount the ways in which trauma is also shaped by interior processes of imaginative investment and identification (which may not be limited to a single position or role). One way to address this imbalance is to consider how viewers can make their identification with images of pain and suffering the basis of socially transformative acts.

Cultural trauma narratives attempt to capture mass identification, but digital media are allowing and revealing a greater diversity of identifications with symbolic wounds. For example, according to W. J. T. Mitchell, the 9/11 attacks initiated a 'war of images' that included the torture of detainees in Abu Ghraib prison, the execution of Saddam Hussein, and the decapitation of hostages by radical Islamists. But Mitchell's account of this war of images, which he claims is "designed to shock and traumatize the enemy" (Mitchell, 2011:2), remains within the logic of perpetrator and victim transferred onto media image and viewer. In Mitchell's analysis, the word "trauma" tends to connote an external force or event impacting on a body or psyche and leaving an injury or wound. Examples of more complex interactions with digital images as symbolic wounds can be seen in political struggles such as the Arab Spring (Wallace, 2016: 80) and Black Lives Matter. Images of violence and death that have been rapidly disseminated through digital networks have provoked communities to engage in political protest and resistance.

Concerns about the psychological effects of media violence need to be understood in the larger context of modern experience. Walter Benjamin's adaptation of Freud's account of trauma in Beyond the Pleasure Principle (1920) stressed that shock had become the "norm" (Benjamin, 2003: 318) in metropolitan culture. Freud proposed that the perceptual apparatus develops a "protective shield" (Freud, 1920: 27) to insulate it from the potentially damaging effects of intrusive stimuli. Only the experience of fright (a sudden and unexpected disturbance) is able to pierce the stimulus shield and thereby cause trauma. Benjamin made a parallel between the protective shield and the camera, which mediates shock and thereby deflects any deeper psychological impact. Ever since the invention of photography viewers have been adjusting their perceptual apparatus to cope with visual shock, leading to an ever-increasing intensity of media effects to capture viewers' attention. The experience of mediated shock in modern consumer societies has accelerated the destruction of earlier cultural taboos and traditional values: what was shocking yesterday 
may be just boring today or next week. Whereas the media-saturated viewer in technologically advanced societies is often assumed to be morally jaded and unresponsive to shock, digital technologies are allowing individuals and groups to transmit and circulate images that can help to re-invigorate community belonging and collective action. Images of police violence against African Americans, for example, may be 'old news' but recent events captured on mobile-phone cameras and posted on the Internet have prompted acts of protest, mourning and retaliatory violence.

\section{Subincision}

In the following discussion I want to reconsider debates about media traumatization by focusing on a specific film that has been used in research on stress films: Subincision Rites of the Arunta, made by psychoanalyst Geza Roheim in 1937 while conducting fieldwork with the Aboriginal tribe in Australia. This film has been repeatedly used in research studies for the purpose of deliberately causing distress to American viewers (Lazarus et al., 1962; Horowitz, 1969). None of these studies has considered the cultural significance of the ritual shown in the film, which Roheim interpreted using Freud's theory of the primal horde: the violence acted out the collective guilt for the murder of the primal father by the younger males (Freud, 1913). In the 1950s, psychoanalyst Bruno Bettelheim discussed the cultural practice of subincision in terms of "symbolic wounds" allowing for self-transformations that enhanced social status and group membership. What such psychoanalytic theories stressed, which was discounted in later laboratory-based research on media traumatization, was the ways in which violence could enable individual self-transformation and group participation.

Digital culture has provided new evidence to suggest that symbolic wounds can be seen as functioning in new technologically-mediated forms. Those who required audiences to watch Subincision expected them to be disturbed by what they saw. Today, however, a quick google videos search of 'subincision' reveals a sub-genre of pornography in which genital mutilation is presented to induce sexual excitement and pleasure, even if for others it may be the object of horror or disgust. Viewers may now use the Internet to access the decapitation videos produced by ISIS, for example, and engage in a range of possible identifications with this violent scenario. These videos are designed, as indeed were the 9/11 
attacks, not only to shock but also to recruit. The Internet allows us to see this range of different negotiations articulated in videos and commentaries posted by non-professional users. For example, counter to the televisual narrative depicting America as the innocent victim of a terrorist attack, the Internet has helped to foster new political communities, such as the 9/11 Truth Movement, that challenge the dominant account.

Jeffrey Alexander has described cultural traumas as "wounds to social identity" (Alexander, 2012: 2). In Subincision the wounds inflicted by genital mutilation define group membership. Psychological studies showed that the viewing of Subincision also produced effects that suggested a shared experience of stress in an entirely different cultural context. Today individuals interact with communication technologies and information networks that allow more private negotiations of thresholds of shock and potential psychological disturbance. The wounds that serve as a basis of identity in tribal communities suggest that violence may continue to define social belonging in more 'advanced' societies, if only in the increasingly dislocated and disembodied forms made possible by technological media. In traditional societies ritual defines social membership; in modern mass societies, mass media construct narratives about collective memory and identity; in networked societies, images can prompt the formation of less centrally-controlled political communities. In each case symbolic wounds play a role in mobilizing and managing group membership. Symbolic wounds now perform an important function in alternative, subcultural and counter-hegemonic narratives about identity in digital culture.

In the study that he led at the University of California observing the psychological stress caused by watching a film, Richard Lazarus selected Subincision. Lazarus describes the contents of the film:

"It depicts one of the important ceremonials of this tribe and very vividly presents a sequence of crude operations performed with a piece of flint on the penis and scrotum of several adolescent boys. The running length is 17 minutes and the film is silent." (Lazarus et al., 1962: 4)

Evaluating the effects of watching this film, Lazarus and his team used personality assessment and measured skin resistance and heart rate and analysed urine samples to assess biochemical response (Lazarus et al., 1962: 4). The screening was followed by a questionnaire-interview asking the subjects to describe their responses to the film and recall what they saw. The participants 
were recruited from psychology courses at the University of California. In their concluding remarks Lazarus et al. suggest that further research might consider "what types of content produce stress in a given amount and pattern and in particular classes of people," given the "nudity of the natives" and "the homosexual implications of their behaviour", and also "what might happen if the same subject watched the film over and over again" (Lazarus et al., 1962: 30). These directions for further research point to questions of cultural meaning and social identity and of technological effects (possibly inducing desensitization) that were excluded from consideration in this initial study.

In his 1969 study, Mardi Horowitz used Subincision again because of its previous use in such experiments. He provides a more detailed description of the film's content:

"The film setting is the Australian bush, and it depicts naked natives engaged in a harsh puberty rite. Scenes of extensive penile surgery, bleeding wounds, and adolescents writhing and wincing with pain are repeated several times. The boys appear to volunteer for this painful procedure, which is conducted by older men.” (Horowitz, 1969: 554)

Both Lazarus and Horowitz mention the explicit visibility of the boys' genitals - something that was taboo in television and Hollywood cinema in the early 1960s (and indeed remains largely so today).

Fifty years later (perhaps due to the cultural impact of the $9 / 11$ attacks) this research was reconsidered in the new context of trauma theory. For example, in his study of Holocaust films, Joshua Hirsch refers to the research by Lazarus and Horowitz that uses Subincision as evidence that "film viewing can lead to symptoms of posttraumatic stress" (Hirsch, 2004: 17). Hirsch combines this proposition with the psychotherapeutic concept of "vicarious trauma" transmitted from a traumatized person to a witness, loved one or family member. Whereas he acknowledges that watching a film can be more emotionally removed than a direct experience of trauma or contact with one who has had such an experience, he nevertheless proposes that the effects of film viewing might include "shock, intrusive imagery, grief, depression, numbing, guilt feelings, and loss of faith in humanity" (Hirsch, 2004: 17). Hirsch's own example of film causing vicarious trauma is the footage taken during the liberation of the Nazi death camps. Hirsch uses earlier research, in which visually taboo material was used to disturb an American audience, to explain how these images of 
emaciated, naked corpses and mass death were traumatic. Psychological studies in which the cultural context was discounted are used by Hirsch to make much larger claims about the cultural trauma of the Holocaust. These broader claims, however, remain within the perpetrator-victim/media-viewer analogy.

Ruth Leys also refers to Horowitz's research in the context of discussing the Holocaust. According to Leys, Horowitz distinguished between different types of images, including "memory fragments, reconstructions, reinterpretations, and symbols" (Leys, 2007: 106). Traumatic images, therefore, need not be understood as the literal trace of an event but can involve role-playing, imagination and fantasy shaped by "unconscious wishes, fears, and memories" (Leys, 2007: 108). Leys argues that the studies by Lazarus and Horowitz that used Subincision also tended towards a literal conception of the image and emphasized the impact of external stimuli, thereby excluding from consideration more complex models of identification (Leys, 2007: 11-112). This argument could also be applied to Hirsch's claims, which do not adequately address how viewers see the Holocaust as part of their cultural identity. These arguments by Hirsch and Leys draw out some of the wider implications of the research on stress films and how it raises questions about historical context and unconscious motivation.

In his discussion of the studies by Lazarus and Horowitz and the later commentary by Leys, Amit Pinchevski emphasizes the central role of media technologies, which tends to be downplayed in all of this research. Pinchevski argues that the understanding of traumatic memories as intrusive images "must owe something to the film apparatus" and "presupposes the technical ability both to record stressful events and to replay these events so as to reproduce stressful effects" (Pinchevski, 2015: 10). Pinchevski then moves from this proposition to pose the question: "Is it possible to be traumatized by watching a catastrophic event on television?" (2015: 10). Pinchevski's emphasis on the role of media is important, but he tends to return to the problem of external stimuli rather than internal identification. Both the psychological research of the 1960s and more recent research in trauma studies has repeatedly returned to Subincision. The following section considers how this film might also prompt us to reconsider the notion of symbolic wounds as a way of understanding media traumatization in digital culture. 


\section{Roheim, Bettelheim and the Symbolic Wound}

The psychological studies of the effects of Subincision did not consider cultural factors as a defining influence on viewers' response. Nor did they acknowledge that the man who produced the film, Geza Roheim, was a close associate of Freud and that his study of initiation rituals in a tribal society was framed by Freudian theories of group identity. Roheim did his clinical training at the Budapest Institute of Psychoanalysis. His conception of "psychoanalytic anthropology" initially involved interpretations of folklore and mythologies, but his ethnographic fieldwork in the South Pacific between 1929 and 1931 led to specific studies of totemism in Australian Aboriginal culture. Roheim was heavily influenced by Freud's theory that the totem animal used in sacrificial ritual was a substitute for the primal father who had been murdered by the young males in the tribe, who were envious of his sexual power over women (Le Barre, 1966: 272-281; Robinson, 1969: 74-146). The sense of shared guilt for this crime led to the establishment of the incest taboo (Freud, 1913). Without attempting to resuscitate Freud's theories of the primal horde, we must nevertheless acknowledge that the repeated use of this film opens up a range of questions about cultural identity, cross-cultural understanding and social belonging that have often been excluded from research on the media transmission of trauma. Mediated trauma is intrinsically bound to these questions.

Roheim's psychoanalytic interpretations of myth and ritual were completely out of favour in the academic environment that later used his film of the subincision rite to induce stress in viewers. An important difference between Roheim's interpretation and the psychological research that uses his film was that he sought to understand Aboriginal ritual (if only from a Eurocentric, evolutionist perspective) whereas for these researchers in the 1960s both the cultural context and symbolic meaning were discounted in the research findings. The historical context for research on stress films would have to include the mass media of television and newspapers that, especially after the revelations of the Nazi death camps in 1945, made available more shocking and disturbing images that pre-war censorship did not allow. This media exposure to violence and catastrophe would further intensify as the 1960s progressed. This was also the era of Cold War ideology and propaganda, with its campaigns of fear about the bomb and mass destruction. 
In his study of initiation rituals, Symbolic Wounds, Bruno Bettelheim discusses the use of subincision by the Arunta with specific reference to Roheim's research. He argues against Roheim's interpretation of the ritual as sadistically imposed by the male elders (as embodiments of the tribal superego) and argues instead that symbolic wounds also enhance cultural identity and empower the participant (Bettelheim, 1955: 124-125, 173-180). To support his argument Bettelheim cites an example from 1950s America:

"The contention that these physical traumata may be felt as painful but not as cruel, and hence not as traumata in the psychological sense, seems supported by the experience of persons undergoing cosmetic plastic surgery. Nobody I know has regarded such surgery as "cruel"; even the pain seems reduced by the desire with which the operations are approached." (Bettelheim, 1955: 83)

Following the logic of Bettelheim's argument one could also argue that the emphasis on the subincision ritual being distressing for Americans to watch fails to acknowledge the positive, enhancing value that the physical transformation has for its participants. As Bettelheim explained, initiation is not only endured and demanded by social hierarchies but is also invested with desire (1955: 93).

Bettelheim suggested an important perspective on the subincision ritual that has been ignored in the subsequent research that uses Roheim's film. If the violence and pain shown in the film could be used to induce discomfort for viewers, then the affirmative value of the ritual for the participants in the film could also potentially be transferred onto the viewing experience. The viewer might endure the stress provoked by a film or media image as a means of self-transformation and group participation. This possibility is implied but not directly acknowledged in Hirsch's discussion of Holocaust films: such visual documents can be used not only to transmit trauma but also in new contexts to affirm Jewish identity through collective acts of grieving (Hirsch, 2004: 17) (or to support more sinister identifications with the perpetrators). As viewers negotiate shocking images on the Internet or disseminated through social media, they can choose to engage with the image in ways that are no longer framed by the discourses of academic researchers, media professionals or politicians.

The second half of the twentieth century was characterized by the emergence of narratives about collective identity linked with media images of war, atrocity, genocide and terror. The breakdown of visual taboos and the political 
uses of fear and terror have been accompanied by the refashioning of national narratives around extreme events such as the Holocaust and 9/11 (Alexander, 2012). In the twenty-first century digital technologies are reconfiguring this use of images and showing how smaller groups and communities can be empowered rather than positioned as passive victims and docile subjects by corporate media or the state.

\section{Digital Wounds: After 9/11}

Digital media allow a proliferation of traumatic images that generate a multiplicity of competing discourses and identifications. Newspapers and network television are losing some of their monopoly on cultural trauma narratives. This development is not all good news. For example, although television and cinema have popularized the Holocaust as a cultural trauma, Internet users can more freely engage with 'alternative' narratives, such as Holocaust denial. A substantial archive of video material on YouTube expounds conspiracy theories related to national traumas such as the assassination of J.F.K. or the 9/11 attacks. Universalizing claims about media traumatization are becoming less convincing due to growing evidence online that media images invite a wider range of responses and interpretations.

When specific events, such as the 9/11 attacks, are given the status of 'traumatic' for large populations, they are elevated from 'just another' image of death and suffering to a cause of psychological stress or a cultural and political crisis. The numerous video recordings made by ordinary citizens of the attacks were subsequently 'captured' by network television and orchestrated into a narrative of national trauma. Images of the attacks were re-played obsessively on television in the hours and weeks that followed them. This repetition helped to establish the events as a social wound inviting collective identification. These recordings, nevertheless, continue to have an afterlife on YouTube, revealing a range of responses to the unfolding events that includes not only distress but also conspiracy theorizing and even amusement.

Mitchell describes $9 / 11$ as an attack on the collective nervous system, producing "a state of panic, anxiety, or depression, or even worse, in a psychotic state, generating hallucinations and paranoid fantasies" (2011: 52). Here Mitchell ascribes a collective psychological state to the American people. But it would be more accurate to see what he calls a "war of images" as conforming to 
a logic that is a long established feature of technologically mediated societies. The ISIS decapitation videos are a clear example of this logic: they present an image of otherness or barbarism, a kind of absolute threat to Western "civilized" values. Yet in their presentation styles, their use of digital cameras and editing, their production of high definition images and musical soundtracks etc., they participate in a visual language that is also used in advertising, music videos and numerous other audio-visual genres. They do not necessarily pose a traumatic intrusion into the collective nervous system or a penetration of collective psychological defences. Rather they participate in a cultural system of image consumption attracted and repelled by shock and voyeuristic fascination. ISIS decapitation videos use ritual slaughter to make a symbolic challenge to Western hegemony. The 'correct' response to these videos in the West is outrage and disgust. But these executions of hostages are performed in the name of many innocent victims of Western military interventions in the Middle East. The videos act out the traditional sovereign power of God and state and in doing so invite others to dedicate their lives to a political struggle. These images, deemed "traumatic" for Western viewers, can also be understood as symbolic wounds inviting positive identification for those who support physical violence as a challenge to Western interests and interventions in the Middle East.

Images of violence and catastrophe are consumed, self-censored and negotiated as a regular occurrence for the contemporary media user. For most media users psychological defences are relatively secure unless the violence or catastrophe poses some immediate threat to their lives or loved ones. Discourses about the psychological vulnerability of large populations can be seen as part of the apparatus of surveillance (Meek, 2016: 145) but they also invite viewers to self-examine and regulate their consumption of stress-inducing images. In a neoliberal society where individuals are required to manage higher levels of risk and therefore also higher levels of fear and anxiety, the media user learns to monitor his/her own resilience, coping mechanisms and levels of distress. The assumption of research on media traumatization appears to be that it measures psychological damage and social cost. But shock and trauma can also be a 'gain', marking a transition into a new identity and increasing the power of the body and the group to sustain itself despite experiencing physical or psychological distress. 
This potential for traumatic images to function as symbolic wounds mobilizing political action became clear in the Arab Spring. In June 2009 Nedā Āghā Soltān was shot during election protests in Iran and her subsequent death, two minutes later, was recorded and posted on the Internet. She became an icon of the political struggle in Iran. In 2010 Khaled Said was beaten to death by police in Egypt. The image of his battered face was recorded on a mobile-phone camera by his brother and circulated to thousands of other phones. A Facebook group "We are all Khaled Said" was also established (Howard \& Hussain, 2011: 38). The new digital image-producing technologies and social networks allowed traumatic images to challenge the authority of the Arab states. The violence perpetrated by the state against the people could be transformed by digital media into symbolic wounds mobilizing struggles for democracy. Established media, particularly the Al Jazeera television network, also played important roles in these political movements. But it was mobile cameras that made it possible for ordinary citizens to capture and circulate traumatic images in ways that eluded the control of the state (Khondker, 2011: 678).

Distinctions between victim, perpetrator, witness and bystander remain important for understanding the shifting subject positions of traumatic identification (Kaplan, 2005: 2), but the relations between these different positions can be complex. To support acts of violence and their technological recording and transmission for political purposes requires identification not only with the perpetrators, but also with those other victims in whose name the violence is perpetrated. Recording and transmitting images of suffering and death may be done out of sympathy with the victims, but can also be used to justify further acts of violence. Looking at any image of violence and suffering may be driven by mere curiosity or voyeuristic desire. What the term "symbolic wound" potentially contributes to our understanding of this shifting dynamic of suffering, perpetrating and witnessing is that wounds have symbolic currency, transmitting cultural meanings about social membership. The meaning of pain is not 'traumatic' in any single sense but is unstable and transformative. To understand mediated trauma we need to move beyond the fundamental distinction between who induces and who suffers pain. Once violence and suffering are recorded and transmitted to viewers the images enter a new symbolic economy that allows for various positions of identification, interpretation and responsive action. 
In America digital media have also made more visible the violence perpetrated by the state against African Americans. In 2016, the shooting and killing by police of Alton Sterling in Louisiana and Philando Castile in Minnesota were both recorded on mobile-phone cameras and posted on social media, again leading to widespread protest and further violence. Castile's actual death was streamed "live" on Facebook by his partner Diamond Reynolds. The protests against the killings of African Americans by police have become associated with the increasing public visibility of Black Lives Matter (BLM), a civil rights movement that began on Facebook in 2013. This use of communication technologies made visible to a potentially unlimited viewing public what many had known about for decades. The killing of African Americans by police, whether judged lawful or not, acts out the state's power over life and death. The videos that show this exercise of state power provoke others to challenge the legitimacy of this violence. As a contemporary civil rights movement BLM is distinguished from its forerunners by its dissociation from established organizations like the church and Democratic Party and by its lack of reliance on charismatic leaders such as Martin Luther King or Jesse Jackson. BLM is a decentralized movement that emphasizes localized action but, as in the Arab Spring, it retains links with corporate media. Celebrity singer Beyoncé posted messages about the shootings of Sterling and Castile on her website and "Black Lives Matter" appears as graffiti in her "Formation" music video. The movement has spread to other countries, for example Australia, where it addresses similar issues for Aborigines.

\section{Conclusions}

The dominance of centrally controlled media such as newspapers, cinema and television made possible the wide dissemination of narratives about collective trauma that were linked to specific images such as those of the Nazi death camps or the Vietnam War. The 9/11 attacks saw a transition to a new multiplicity of recordings of the event made by ordinary citizens that were later orchestrated in presentations by television news and documentary. More recent developments such as the Arab Spring, the emergence of Black Lives Matter as an international movement, and the propaganda videos produced by ISIS, show that 'traumatic' images can be captured by groups and used to mobilize political struggles that challenge hegemonic power. 
Psychological research on media traumatization involved deliberately inducing stress by showing violent and taboo images to unprepared audiences. This research was extended to entire populations after the 9/11 attacks. Psychoanalytic perspectives on the transmission of trauma using photographs and audio-visual media suggest a more complex understanding of cultural identification. Academic developments informed by psychoanalysis in trauma and Holocaust studies, however, have often tended to reproduce the model of trauma as external stimuli impacting on viewers. Developments in digital culture allow us to see a more proactive production and mobilizing of traumatic images by a more diverse range of individuals and groups. The idea of 'symbolic wounds' as a means of self-transformation and group participation may offer a useful corrective to the dominant idea of cultural trauma.

Individual media users and social networks share potentially shocking or disturbing images as a means of constructing social identity. What research in the 1960s called stressful can now be seen as enhancing knowledge, social participation and pleasure. Modern visual media has played a significant role in redefining political identity through images of violence and catastrophe. Digital media technologies are enabling new modes of social and political participation in which 'traumatic' images define what constitutes a threat, what is permissible to look at, what can be endured and what can mobilize collective identification and political struggle. 


\section{References}

Alexander, J. (2012). Trauma: A Social Theory. Cambridge: Polity.

Benjamin, W. (2003). Selected Writings Volume 4, 1938-1940. H. Eiland \& M. Jennings (Eds.) Trans. E. Jephcott et al. Cambidge, MA and London: Harvard University Press.

Bettelheim, B. (1955). Symbolic Wounds: Puberty Rites and the Envious Male. London: Thames and Hudson.

Caruth, C. (1996). Unclaimed Experience: Trauma, Narrative and History. Baltimore and London: Johns Hopkins University Press.

Felman, S. \& Laub, M. D. (1992). Testimony: Crises of Witnessing in Literature, Psychoanalysis and History. New York and London: Routledge.

Freud, S. (1913/1953-74). Totem Taboo. In Strachey, J. (ed.), The Standard Edition of the Complete Psychological Works of Sigmund Freud, Volume 13 (pp. 1-101). London: Hogarth Press and the Institute of Psychoanalysis.

Freud, S. (1920/1953-74). Beyond the Pleasure Principle. In Strachey, J. (ed.), The Standard Edition of The Complete Psychological Works of Sigmund Freud, Volume 18 (pp. 1-64). London: Hogarth Press and the Institute of Psychoanalysis.

Hirsch, J. (2004). Afterimage: Film, Trauma and the Holocaust. Philadelphia: Temple University Press.

Holmes, E. \& Bourne, C. (2008). Inducing and Modulating Intrusive Emotional Memories: A Review of the Trauma Film Paradigm. Acta Psychologica, 127: 553-566.

Horowitz, M. (1969). Psychic Trauma: Return of Images after a Stress Film. Archives of General Psychiatry, 20(5): 552 -559.

Howard, P. \& Hussain, M. (2011). The Upheavals in Egypt and Tunisia: The Role of Digital Media. Journal of Democracy, 22(3): 35-48.

Kaplan, E. A. (2005). Trauma Culture: The Politics of Terror and Loss in Media and Literature. New Brunswick, New Jersey and London: Rutgers University Press. 
Khondker, H. (2011). Role of the New Media in the Arab Spring. Globalizations, 8(5): 675-679.

Lazarus, R., Speisman, J., Madkoff, A. \& Davison, L. (1962). A Laboratory Study of Psychological Stress Produced by a Motion Picture Film. Psychological Monographs: General and Applied, 76(34): 1-36.

Le Barre, W. (1966). Geza Roheim, 1891-1953: Psychoanalysis and Anthropology. In Alexander, F., Eisenstein, S. \& Grothohn, M. (eds.), Psychoanalytic Pioneers (pp. 272-291). New York and London: Basic.

Leys, R. (2000). Trauma: A Genealogy. Chicago and London: University of Chicago Press.

Leys, R. (2007). From Guilt to Same: Auschwitz and After. Princeton and Oxford: Princeton University Press.

Lifton, R. (1967). Death in Life: Survivors of Hiroshima. New York: Random House.

Lifton, R. (1973). Home form the War: Vietnam Veterans: Neither Victims nor Executioners. New York: Simon and Schuster.

Meek, A. (2010). Trauma and Media: Theories, Histories and Images. New York and London: Routledge.

Meek, A. (2016). Biopolitical Media: Catastrophe, Immunity and Bare Life. New York and London: Routledge.

Mitchell, W. J. T. (2011). Cloning Terror: The War of Images, 9/11 to the Present. Chicago and London: University of Chicago Press.

Morpurgo, V. (2016). From Prometheus to Big Brother: A Prosthetic God, Truly Magnificent. In Marzi, A. (ed.), Psychoanalysis, Identity, and the Internet: Explorations and the Internet (pp. 33 -50). London: Karnac.

Neria, Y., Di Grande, L. \& Adams, B. G. (2011). Posttraumatic Stress Disorder Following the September 11, 2001, Terrorist attacks: A review of the Literature among Highly Exposed Populations. American Psychology, (66)6: 429-446.

Pinchevski, A. (2015). Screen Trauma: Visual Media and Post-traumatic Stress Disorder. Theory, Culture and Society, 33(4): 51-75.

Poster, M. (2006). Information Please: Culture and Politics in the Age of Digital Machines. Durham and London: Duke University Press. 
Robinson, P. (1969). The Freudian Left: Wilhelm Reich, Geza Roheim, Herert Marcuse. New York, Evanston and London: Harper and Row.

Roheim, G. (1950). Psychoanalysis and Anthropology: Culture, Personality and the Unconscious. Madison, CT: International Universities Press.

Sontag, S. (1977). On Photography. New York: Farrar, Straus and Giroux.

Trimarco, J. \& Depret, M.H. (2005). Wounded Nation, Broken Time. In Heller, D. (ed.), The Selling of 9/11: How a National Tragedy Became a Commodity (pp. 27-53). New York: Palgrave MacMillan.

Wallace, P. (2016). The Psychology of the Internet (Second Edition). New York: Cambridge University Press.

Young, A. (2007). Posttraumatic Stress Disorder of the Virtual Kind: Trauma and Resilience in Post-9/11 America. In Sarat, A., Davidovitch, N. \& Albertstein, M. (eds.), Trauma and Memory: Reading, Healing, and Making Law (pp. 21-48). Stanford: Stanford University Press. 
Media Traumatization, Symbolic

Allen Meek

Wounds and Digital Culture 